\title{
IDENTIFICACÃO E REPRESENTAÇÃO DE CONCEITOS POR MEIO DE TERMOS
}

\section{IDENTIFICATION AND REPRESENTATION OF CONCEPT THROUGH TERMS}

Brígida Maria Nogueira Cervantes ${ }^{\dagger}$

\begin{abstract}
RESUMO
Apresenta um modo de identificação e representação de conceitos por meio de termos elaborado conforme orientações teóricas e metodológicas de normas terminológicas e documentárias. Destaca a análise conceitual e síntese como processo utilizado para a identificação e representação de conceitos tendo como base os contextos encontrados na literatura e validados do ponto de vista conceitual por pesquisadores e especialistas da área em estudo. Para a identificação de conceitos, é necessário que o processo de coleta de termos seja realizado de forma minuciosa. A análise de contextos é parte fundamental para que ocorra a síntese. Finaliza enfatizando que os cientistas se apropriam das palavras dando a elas um sentido específico. Portanto, palavras comuns podem ser utilizadas como conceitos. As palavras podem se transformar em conceitos no âmbito de perspectivas teóricas específicas.
\end{abstract}

Palavras-Chave: Sistema de Conceitos. Análise conceitual. Terminologias.

\section{ABSTRACT}

It presents a way of identifying and representing concepts through terms elaborated according to theoretical and methodological guidelines of terminological and documentary standards. Highlights conceptual analysis and synthesis as a process used for the identification and representation of concepts based on the contexts found in the literature and validated from the conceptual point of view by researchers and specialists in the subject area. For the identification of concepts, it is necessary that the process of collecting terms be carried out in a meticulous manner. The analysis of contexts is a fundamental part to occur the synthesis. It concludes by emphasizing that scientists appropriate of words by giving them a specific meaning. Therefore, common words can be used as concepts. Words can become concepts within specific theoretical perspectives.

Keywords: Concept System. Conceptual Analysis. Terminologies.

Artigo submetido em 21/10/2020 e aceito para publicação em 17/11/2020

1 Docente permanente no Programa de Pós-Graduação em Ciência da Informação. Universidade Estadual de Londrina, Brasil. ORCID https://orcid.org/0000-0001-7356-1798. E-mail: brigidacervantes@gmail.com 


\section{INTRODUÇÃ̃O}

0 conceito é um conjunto de características que traduzem qualidades próprias e peculiares das coisas, objetos ou pessoas designadas. A base das ciências e suas especificidades são representadas pelos conceitos. Sendo assim, o conjunto de termos de um domínio específico do conhecimento, de uma área, representa 0 corpo conceitual, denominado também de terminologias.

Segundo Rondeau (1984), a Terminologia estuda os conceitos das línguas de especialidade. 0 conceito pode ser descrito como uma representação abstrata composta de um conjunto de traços comuns essenciais a um grupo de entidades (objetos ou ideias) é obtido na subtração das características individuais dessas entidades. Os traços comuns essenciais são representados por três elementos: a natureza, a forma e a função (RONDEAU, 1984, p. 22, tradução nossa).

Tendo como fundamento o modelo de Rondeau, destaca-se do primeiro grupo de entidades, o dos "objetos". Considera-se como exemplo o conceito de computador. Inicialmente, deve-se estudar todos os tipos de computadores existentes e suas características individuais. Algumas não essenciais, como cor, tamanho e modelo. Observa- se que as classes dos objetos têm traços comuns essenciais. Exemplo: Quanto à natureza, um computadoré uma máquina eletrônica. Quanto à forma, o computador mantém uma arquitetura variável ao longo do tempo, como a diminuição do seu tamanho. Mas suas partes básicas estão presentes nos vários tipos de computadores. Com a evolução tecnológica, os mais variados tipos de computadores foram criados, denominados 0 laptop, o notebook, o netbook, o tablet, o smartphone, entre outros. Por este motivo, é necessário que para cada conceito haja uma definição precisa, bem adaptada, a mais clara possível para os termos.

0 segundo grupo de entidades, 0 das "ideias", possui um sentido bastante amplo, visto que abrangem procedimentos, comportamentos, qualidades, atividades, entre outros. Nesse contexto, considera-se que os conceitos sejam mais difíceis de discernir. Toma-se o exemplo da palavra "angústia", em Barros (2016), quando a emprega na vida diária não se pensa em conceito, mas no âmbito da teoria da Filosofia e ou da Psicologia a palavra angústia desempenha o papel de conceito. Os filósofos existencialistas concordam em suas análises em centralizar 0 conceito de angústia, que ocupa uma posição básica que distingue um filósofo existencialista de outro (BARROS, 2016). 


\section{MODOS DE REPRESENTAÇÃO DE CONCEITO POR MEIO DE TERMOS}

Conforme Cabré (1999), o profissional da informação, em conjunto com o terminológo, o informático e o profissional de uma área em estudo, compõe grupo multidisciplinar de trabalho para estudar os meios de nomear os conceitos em uso nas atividades especializadas, contando com a ajuda de palavras e expressões da vida comum.

De acordo com Rondeau (1984), no conjunto de palavras e expressões de uma determinada língua, os termos representam uma proporção cada vez mais importante em relação às palavras ou expressões da língua comum. Barros (2016) argumenta que para estabelecer os conceitos de uma ciência se leva um longo tempo. É um processo que envolve a comunidade de um determinado campo de estudo. Os cientistas nem sempre criam os termos que vão servir para esclarecer os conceitos, mas se esforçam para escolher palavras da língua comum que funcionarão como conceitos, as quais servirão para suas perspectivas teóricas mais específicas. Os usuários poderão dar origem em forma de palavras ao que servirá de base para a elaboração de conceitos em um determinado campo do saber.

Em razão disso, os cientistas se apropriam das palavras dando a elas um sentido específico. Portanto, palavras comuns podem ser utilizadas como conceitos. As palavras podem se transformar em conceitos no âmbito de perspectivas teóricas específicas (BARROS, 2016).

Vale ressaltar o termo "conhecimento", explicitado por Cervantes e colaboradoras (2010, p. 27), como um "Conjunto de informações que estão armazenadas na mente humana, inclui reflexão, síntese e contexto". A elaboração desta definição fundamentou-se no contexto de revista especializada da área de Ciência da Informaç̧ão. Vimos que a definição supracitada apresenta especificações semânticas sobre 0 termo, estabelecendo sua relação com o conceito.

Barros (2016) menciona Dahlberg para reportar-se sobre as dimensões do conceito, composto pelo referente, termo e características. 0 referente é a unidade do pensamento da realidade observável; o termo é a palavra utilizada para comunicar e as características são as propriedades atribuídas conceitualmente.

Para um melhor entendimento, o conceito, na dimensão de referente, define-se como unidade de pensamento. Autores como Dahlberg (2007) e Barité (2001; 2011), reconhecem o conceito como unidade de conhecimento, isso porque é construído a partir das relações de afinidade com outros conceitos, conforme sua vizinhança. 0 conceito não pode ser considerado um elemento isolado e por isso se torna um enunciado (BUFREM; GABRIEL FILHO, 2011). 
0 conceito, na dimensão de termo, refere-se à palavra utilizada para a comunicação e isso acontece quando um conceito bem delineado a partir de uma palavra está organizado sistematicamente em algum campo do saber. Assim, para que as palavras se tornem conceitos, é necessário que ultrapassem a condição de unidade de comunicação para unidade de conhecimento. Isso requer estar no centro de determinada análise ou campo de estudos. Dessa forma, o uso das palavras ocorre em conformidade com seus diversos usos e aplicações, uma vez que remeterá ao significado da palavra e também poderá possibilitar outras formas de ver as palavras por meio de estudo ao associar conceitos vizinhos ou distantes (BARR0S, 2016).

0 conceito, na dimensão de características, é formado por uma combinação de propriedades atribuídas conceitualmente para uma ou mais coisas, objetos ou pessoas designadas. É o resultado de uma proposição dentro de um domínio do saber, uma vez que o conceito se define pela posição que ocupa em alguma estrutura de conceitos (BARR0S, 2016).

Logo, o conceito é relevante para qualquer área do conhecimento, pois, como unidade de conhecimento, pode vir a construir o sistema de pensamento, ou teoria, ou sobre determinadas coisas, objetos ou pessoas designadas. Já, como unidade de comunicação, pode vir a possibilitar o diálogo entre autores e diferentes realidades. Por fim, as características vêm a promover a compreensão de um conceito (BARROS, 2016).

Assim, os conceitos têm a função de auxiliar na organização dos conteúdos possibilitando a sua sistematização. Para a organização de um domínio, desde a representação até a sua recuperação, estudam-se os conceitos que compõem esse campo do conhecimento e as relações que se estabelecem entre eles. (CERVANTES, 2006).

Conforme Dias e Naves (2013), para definir um determinado conceito deve-se realizar procedimentos lógicos, ou seja, é necessária a operação intelectual do conhecimento, uma vez que o conceito é essencial para que se possa efetuar a análise e a compreensão nas diferentes áreas do conhecimento, em que uma série de ideias subordinadas é ativada para chegar a uma conclusão geral sobre 0 objeto em estudo.

Assim, tendo como base as seis funções dos conceitos descritos por Barros (2016), percebeuse também, que é através de conceitos que se identificam outros conceitos, dado que tais funções são inerentes ao processo cognitivo para identificar conceitos. 
Figura 1 - Seis funções dos conceitos.

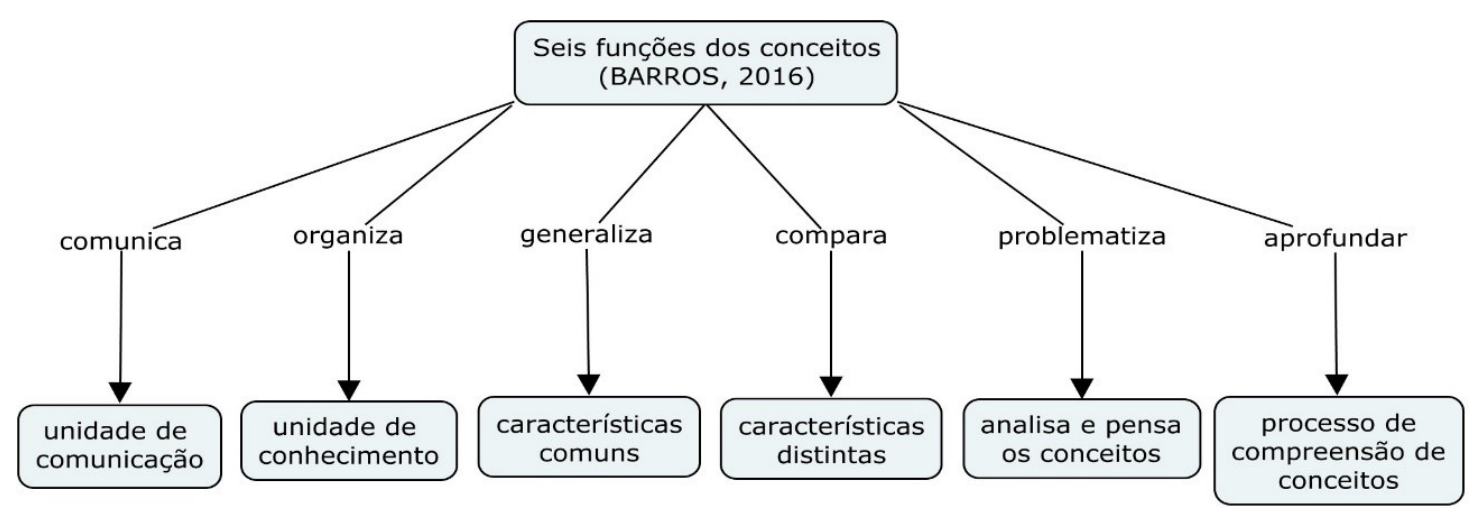

Fonte: Elaboração própria fundamentado em Barros (2016, p. 36).

De acordo com Oliveira (2001, p. 34), o conceito "é uma imagem subjetiva do mundo objetivo, revela aspectos essenciais, universais do objeto" e são vários os processos mentais como a análise, a síntese, a abstração e a generalização para se formar um conceito. Para efeito deste estudo enfatiza-se o processo de análise e síntese, conforme a Figura 2.

Figura 2 - Processo mental para formar um conceito.

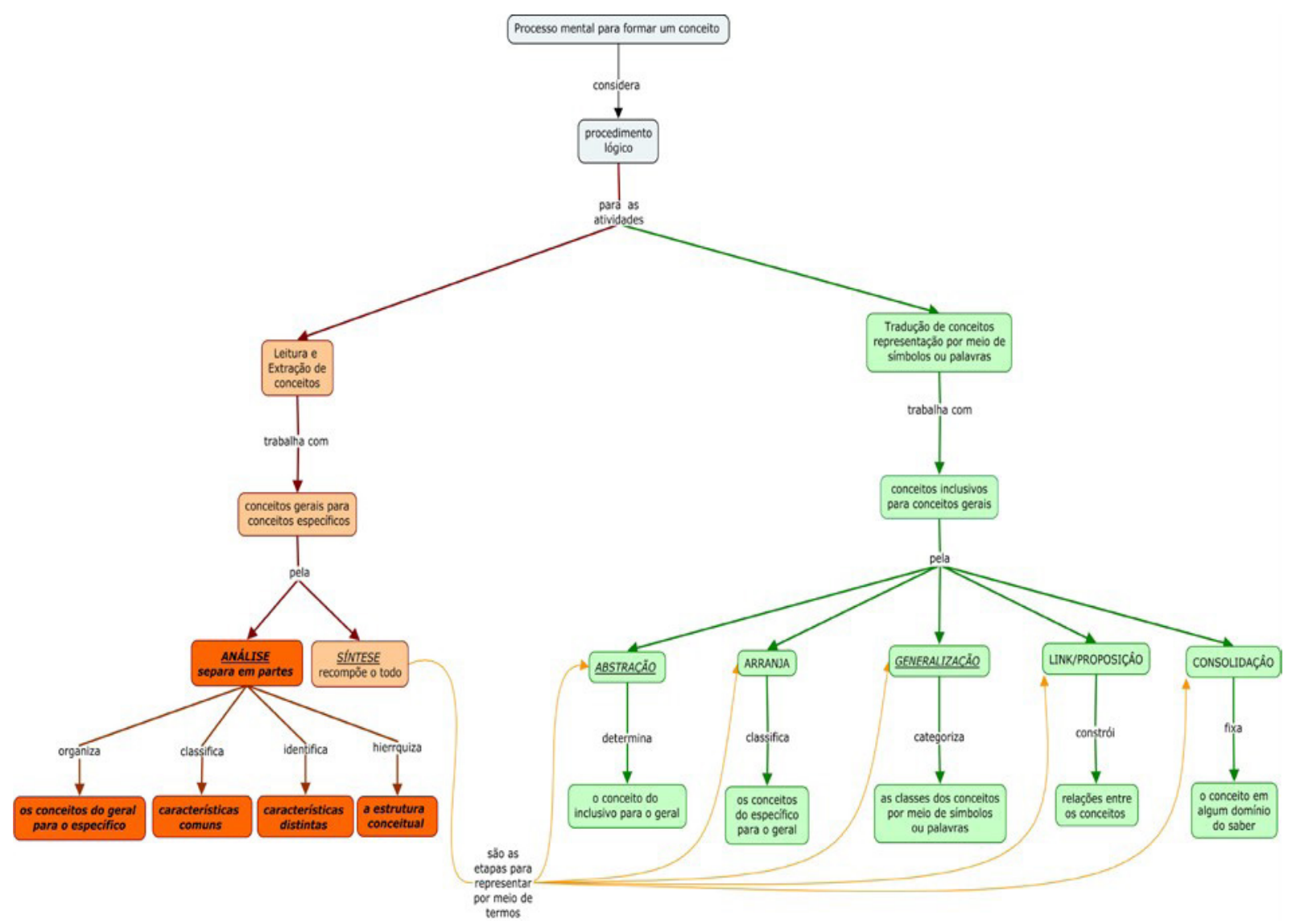

Fonte: Elaboração própria fundamentada em Rodrigues e Cervantes (2017). 
Neste processo mental, para formar um conceito, observou-se a necessidade da leitura do documento e a extração de conceitos, visto que nesta fase trabalha-se com os conceitos gerais para os conceitos específicos por meio da análise e síntese. Portanto, o trabalho mental tem início por meio da percepção e da análise em que organiza, seleciona, ou separa em partes (decompõe) os conceitos do geral para o específico; classifica e elege características comuns; identifica as características distintas e hierarquiza a estrutura conceitual.

Continuando, predispõe-se para o processo da síntese em que se recompõem as partes para 0 todo por meio da abstração ao determinar o conceito do inclusivo para o geral e também ao classificáIo. Seguido pela etapa de generalização que categoriza as classes dos conceitos por meio de palavras ou símbolos, proporcionando a relação entre os conceitos (link/proposição) e finalizando por meio da consolidação, que nada mais é que reter e representar o conceito em algum domínio do saber.

Segundo Wilson (2001), a técnica de análise de conceitos foi projetada para enfrentar e esclarecer conceitos. Em razão disso, oferece métodos especializados e adequados de ensino, de modo que se possa aprender e aplicar a técnica para responder às muitas questões que têm sido propostas. A análise conceitual é muito útil para estimular e tornar mais eficaz a comunicação, considerada como um saber especializado com técnicas próprias. Sem essas técnicas, haveria dificuldade em abordar as questões gerais e as perguntas que envolvem um conceito abstrato.

A representação de conceitos por meio de termos busca expor o conhecimento surgido nas ciências. Dessa forma, a representação ou a tradução de conceitos materializa a construção do conhecimento. Nesse contexto, segundo Fujita (2008, p. 6), a representação do conhecimento é compreendida por Dahlberg como "estrutura lógica de representação conceitual e, também, o resultado da identificação de conceitos por termos determinados". Deste modo, entende-se que a representação do conhecimento possui duas características diferentes: a representação do conhecimento por meio de conceitos e a representação da estrutura lógica do conhecimento.

Assim, a representação de conceitos pode vir a concretizar-se por meio de Sistemas de Conceitos. Neste sentido, Barité (2001, tradução nossa) corrobora por meio das seguintes Premissas: premissa 7 (o conhecimento se expressa por meio de conceitos e se organiza mediante Sistemas de Conceitos); premissa 8 (o conhecimento é sempre registrado em documentos, como um conjunto de dados disponíveis, o que permite seu uso indiscriminado); premissa 9 (os Sistemas de Conceitos se organizam para fins científicos, funcionais e de documentação); e premissa 10 (as leis que regem os Sistemas de Conceitos são uniformes e previsíveis e, se aplicam por igual em qualquer disciplina). Menciona o Sistema de Conceitos, no qual o conhecimento é organizado, e que pode ser utilizado em 
qualquer área do conhecimento. Possui processo cognitivo semelhante para identificar o conteúdo de documentos e trabalha com os conceitos e suas relações.

Neste estudo foram identificados, por meio do processo de análise conceitual e síntese, alguns termos presentes em instrumento terminológico-documentário, elaborado conforme orientações de normas terminológicas e documentárias, fundamentados nos contextos encontrados e validados do ponto de vista conceitual por pesquisadores e especialistas da área da Moda.

\section{ANÁLISE CONCEITUAL E SÍNTESE}

A análise conceitual ou análise terminológica propõe-se a determinar, primeiramente, se o termo pertence ao vocabulário do domínio estudado e em seguida ao subdomínio definido. Desse modo, uma pesquisa sobre termos do domínio da Moda, subdomínio Têxtil reuniu os termos que pertenciam especificamente a este subdomínio ou fazendo um recorte a um campo semântico ou temático, ou ainda, a um determinado aspecto.

A estrutura conceitual permitiu averiguar se o termo pertence a um domínio especializado. Sendo assim, estabeleceu-se um sistema de conceitos em que as unidades terminológicas foram interligadas.

De acordo com Cabré (1993), é preciso estabelecer a estrutura conceitual do subdomínio, objeto de estudo e o representar graficamente. 0 sistema de conceitos deverá estar integrado, e pesquisas minuciosas devem ser realizadas para estabelecer o campo nocional do domínio em estudo. Quanto mais detalhada e rigorosa for a estrutura conceitual, melhor será o trabalho posterior com os termos. A seguir, apresenta-se uma estrutura conceitual do estudo realizado:

Figura 3 - Estrutura conceitual do domínio da Moda

\begin{tabular}{|l|l|}
\hline \multicolumn{2}{|c|}{$\begin{array}{c}\text { DOMÍNIO } \\
\text { MODA }\end{array}$} \\
\hline SUBDOMÍNIOS & \multicolumn{1}{c|}{ CATEGORIAS TEMÁTICAS } \\
\hline TÊXTIL & Fiação. Tecelagem. Tecidos. Aviamentos. \\
\hline VESTUÁRIO & Vestimentas. Modelos. Acessórios. Calçados. Estilos. \\
\hline PROCESSO DE PRODUÇÃO & Criação. Modelagem. Corte. Montagem. Acabamentos. \\
\hline FUNÇÕES & Profissões. Empresas do ramo. Atividades. Eventos. \\
\hline
\end{tabular}

Fonte: Elaboração própria fundamentada em Raimundo (2003). 
Neste estudo, considerou-se a Norma ISO 1087 (2000) que define: "Domínio como parte do saber cujos limites são estabelecidos conforme um ponto de vista particular". Já o subdomínio representa cada uma das subdivisões de uma das partes do saber. Assim, estabeleceram-se as categorias temáticas dos subdomínios: Têxtil, Vestuário, Processo de Produção e Funções.

0 subdomínio Têxtil representa tudo o que está relacionado à produção e fabricação do tecido. Representa o conjunto da indústria têxtil. As categorias temáticas levantadas foram: fiação, tecelagem, tecido e aviamento.

Fiação - processo que transforma as fibras naturais, químicas ou suas misturas em fios. Esta categoria trata das matérias-primas e dos tipos de fios.

Tecelagem - local onde os fios são recebidos para serem entrelaçados e transformados em tecidos que podem ser panos, fitas, telas, entre outras. Esta categoria temática trata dos termos técnicos da indústria da tecelagem.

Tecido - produto do tear. Urdido; preparado; apropriado; é o material obtido pelo conjunto de fios entrelaçados. 0 tecido é a trama de fios. Nesta categoria vê-se o design têxtil, tipos de tecidos, formas, texturas, estamparias e processos de acabamento.

Aviamento - material necessário para a confecção de uma peça de roupa, ficando nela permanentemente. Exemplos: apliques, fitas, botões, entre outros. Esta categoria apresenta os mais variados tipos de aviamentos desde os clássicos até os mais atuais.

Já o subdomínio Vestuário refere-se ao conjunto das peças que compõem o traje, as roupas e os complementos que as acompanham. Neste subdomínio levantaram-se as seguintes categorias: vestimenta, modelo, estilo, acessório e calçado.

Vestimenta - peça de roupa utilizada para cobrir partes do corpo. Exemplos: vestido, calça, saia, entre outros.

Modelo - peça de indumentária criada por estilista ou casa de modas. Exemplos: calça skinny, vestido tubinho sino, blusa assimétrica, entre outras.

Estilo - conjunto de tendências e características formais e estéticas da moda em determinadas épocas ou grupos sociais e culturais. Exemplos: estilo alta-costura, casual- look, andrógino, entre outros.

Acessório - peça variada que completa a harmonia do conjunto do vestuário.

Calçado - peça de vestuário, feita de couro, Iona ou outro material, que serve para vestir o pé.

0 subdomínio Processo de Produção inicia-se pela criação, a modelagem, o corte, a montagem ou costura e acabamentos. 
Criação - concepção, invenção e formatação das roupas.

Modelagem - representação por meio de modelo ou molde. Corte - ato de cortar e talhar uma roupa.

Montagem ou Costura - junção das partes da peça, por meio de pontos feitos com linha, fio e agulha.

Acabamento - finalização da peça de roupa ou o seu aperfeiçoamento.

0 subdomínio Funções está ligado à execução de tarefas e ofícios. Neste subdomínio destacamse as categorias temáticas: profissões, empresas do ramo, atividades e eventos.

Profissões - denominações dos cargos e profissões.

Empresas do ramo - denominações das empresas e organizações.

Atividades e eventos - denominações dos eventos relacionados ao domínio da Moda.

Para Cabré (2000, tradução nossa), as unidades terminológicas têm a capacidade de referenciar desde que estejam contextualizadas, visto que os conceitos de um mesmo âmbito especializado mantêm entre si relações que constituem a estrutura conceitual do domínio estudado. 0 valor de cada termo depende de sua posição relativa, tal como acontece com as unidades da linguagem geral. 0 texto será o ponto de partida considerando sua estrutura e suas condições discursivas, isto porque 0 texto manifesta o domínio de conhecimento por meio da representação pela escrita independente de seu suporte.

\subsection{Termos e Contextos}

Os termos são considerados unidades de base da Terminologia e podem ser formados de uma ou mais palavras. Segundo Dubuc (1985), o termo deve estar vinculado a real necessidade de expressão e comunicação do usuário, do pesquisador de uma determinada disciplina, de uma técnica ou de uma ciência em desenvolvimento; por esse motivo assume muitas vezes uma estrutura sintagmática. Neste estudo foram analisados alguns termos básicos do vocabulário da Moda.

De acordo com Dubuc (1985), a situação em que os termos se encontram transcende a noção sobre o plano da comunicação, assim, uma mesma noção poderá encontrar marcas diferentes segundo sua área de utilização. 0 termo adquire a sua função semântica a partir da sua associação em um domínio específico do conhecimento. 
Não se pode analisar os termos desvinculados das condições nas quais eles foram produzidos e do tipo de discurso de onde eles foram extraídos. Desse modo, os contextos são fundamentais uma vez que ilustram o uso real de um termo, exprimem uma ideia completa sobre ele. Os contextos devem ser escolhidos em função de suas qualidades e servem para elucidar a denominação e transmitir com clareza o conceito que o termo representa.

0 contexto de ocorrência é o conjunto de condições de uso da língua, envolve simultaneamente emissor e receptor, em uma determinada situação, permitindo a redução de erros na identificação e no recorte dos termos. Conforme Rondeau (1984), os contextos, podem ser: explicativos, associativos ou definitórios.

0 contexto explicativo é o que revela de maneira resumida a natureza ou a constituição, o objetivo ou a finalidade, 0 aspecto ou a aparência do termo. Já o associativo caracteriza-se pela ausência de descritores significativos que relacionam o termo ao seu contexto, este retoma o campo de aplicação do termo através de associações que se interagem na frase. 0 contexto definitório explicita o conceito do termo de forma precisa, a sua definição encontra-se dentro do tópico textual (RONDEAU, 1984).

\section{ANÁLISE E APRESENTAÇÃO DOS RESULTADOS}

Para esta análise foram selecionados termos e contextos do vocabulário da Moda, subdomínio Têxtil ${ }^{2}$ tendo como fundamento a teoria de Rondeau (1984), destacando os contextos definitórios, explicativos e associativos.

1) Contexto definitório

Termo: Tecido

Contexto: 0 <tecido> é um produto artesanal ou industrial resultado da tecelagem de fios de Iã, seda, algodão, ou outra fibra natural, artificial ou sintética, e que é usado na confecção de peças de vestuário, de artigos de decoração, de embalagens entre outros.

Definição: Textura resultada do entrelaçamento de fios e ou de fibras diversos.

Nota explicativa: Do latim textura. A textura é a disposição e a ordem dos fios na tela. No setor têxtil, 0 termo também é usado para fazer referência à operação de tecer e à superfície de uma peça de roupa (HOUAISS, 2009).

0 contexto definitório facilitou 0 entendimento do conceito para a redação da definição apresentando dados com indicações precisas sobre a noção do termo estudado. Neste exemplo,

20 estudo dos termos identificados foi realizado no âmbito do projeto "Métodos e Técnicas de Pesquisa em Terminologia: uma experiência com o vocabulário da Moda". 
o termo genérico "tecido" foi definido de maneira sucinta com base no contexto. Segundo Pavel e Nolet (2001), "a definição terminológica é uma fórmula lexicográfica sucinta que descreve os traços semânticos distintivos de um conceito".

Outros exemplos de contextos definitórios:

Termo: Tecido de malha

Contexto: "Os <tecidos de malha> são artigos produzidos a partir do entrelaçamento de fios exemplos consecutivos, no sentido da trama ou do urdume" (MALUF, 2003, p. 119).

Termo: Fio

Contexto: "<Fio> é um termo genérico para uma mecha contínua de fibras têxteis..." (MALUF, 2003, p. 65).

A identificação do termo depende do contexto, pois recebe seu significado em relação às outras palavras do texto e indica a associação do termo ao seu domínio específico. Portanto, os contextos definitórios forneceram informações relevantes e especificações semânticas sobre os termos, estabelecendo a relação entre o conceito e o termo. Segundo Rey (1979), termo e definição possuem um traço em comum, pois designam em suas origens o estabelecimento de um limite. Assim, a definição deve ser uma descrição funcional do conceito.

Cabe esclarecer que as notas explicativas incluídas no vocabulário são de caráter enciclopédico e visam apresentar informações que não estão incluídas nas definições.

2) Contexto explicativo

Termo: Malharia por trama

Contexto: "0 tecido de malha em <malharia por trama> é obtido a partir de um único fio que faz evoluções pelas diversas agulhas, formando uma carreira de sucessivas laçadas, que se entrelaçam com as malhas correspondentes da carreira anterior" (MALUF, 2003, p. 154). 0 contexto explicativo em "malharia por trama" informa de maneira sumária sobre a natureza ou um determinado aspecto do termo estudado. Neste contexto, tem-se a finalidade e o modo como "malharia por trama" é efetivada e formada.

3) Contexto associativo

Termo: Linha trapézio

Contexto: "A <linha trapézio>, como seria conhecida, revolucionou a moda com vestidos de ombros estreitos e saias amplas, dando mais conforto e liberdade" (ELLE, fev., 2002, p. 75). 0 contexto associativo caracteriza-se pela ausência de descritores. Neste caso, o termo estudado é relacionado a um campo de aplicação preciso pela associação com os termos que o rodeiam. Outros exemplos: 
Termo: Crepe georgette

Contexto: "0 modelo de <crepe georgette> tem renda e babadinhos no colo, nos punhos e na barra". (MANEQUIM, 2002, n.509, p. 34).

\section{Termo: Prêt-à-porter}

Contexto: "O luxo hoje no <prêt-à-porter> é tratado de maneira diferente: de uma forma que se aproxima da alta costura, com a riqueza dos tecidos, acessórios e bordados". (WORLD FASHION, fev. 2002, p. 32).

Para a identificação de conceitos, é necessário que o processo de coleta de termos se realize de forma minuciosa e árdua. Portanto, a análise de contextos é parte fundamental para que ocorra a síntese, conforme a representação por meio do mapa conceitual a seguir.

Figura 4- Representação da análise de termos e contextos do domínio da Moda

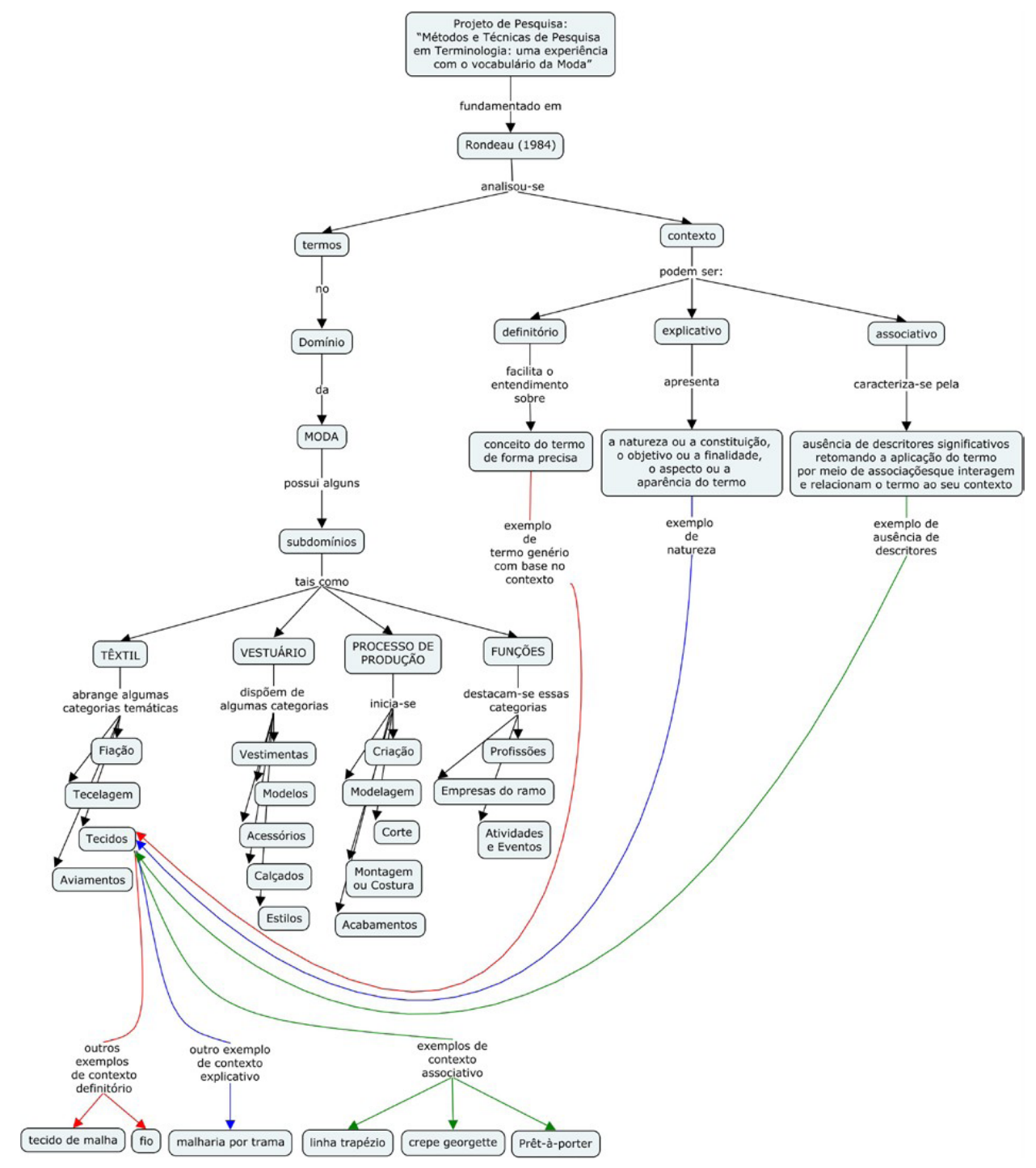

Fonte: Elaboração própria fundamentada em Raimundo (2003). 
A análise e síntese conceitual sendo realizada possibilita enriquecer semanticamente os termos coletados, pois na etapa de levantamento dos dados que acontece por meio de contextos. 0 contexto oferece o conceito sobre cada termo e orienta para o domínio da utilização do termo, as modalidades e as condições de seu emprego. 0 contexto fornece os elementos que permitem associar o termo a um domínio específico, provendo concorrentes, no mínimo reveladores, do meio onde o termo é usado.

Sendo assim, é necessário identificar os traços semânticos importantes: natureza, finalidade, função, matéria, ou ainda empregos característicos, formas e expressões, pertencentes propriamente ao vocabulário utilizado no domínio/subdomínio estudado. Desse modo, é no contexto que deve residir a maior preocupação do grupo de trabalho que atua com pesquisa terminológica.

\section{CONCLUSÃO}

Tendo em vista a análise e síntese de conceitos, procurou-se revelar, por meio do contexto, 0 campo conceitual dos termos, que neste estudo contemplou o vocabulário da Moda. Estabeleceu-se a estrutura conceitual, para sistematizar a análise e síntese dos termos e também utilizou-se do instrumento Mapas Conceituais para melhor visualização da representação deste domínio do conhecimento.

Os termos adquirem a sua função semântica a partir da sua associação em um domínio específico do conhecimento, tendo como base os contextos. Por este motivo, buscou-se representar os termos vinculados às condições em que ocorrem. Os contextos são fundamentais uma vez que ilustram o uso real de um termo e devem ser escolhidos em função de suas qualidades, servindo para elucidar a denominação e transmitir com clareza o conceito que o termo representa.

\section{REFERÊNCIAS}

BARROS, J. A. Distinção entre simples palavras e conceitos. In: Os conceitos: seus usos nas ciências humanas. Petrópolis, RJ: Vozes, 2016. p. 25-31.

CABRÉ, M.T. La terminología. Teoría, metodología, aplicaciones. Barcelona: Editorial Antártida/ Empúries, 1993.

CABRÉ, M.T. Terminologie et linguistique: la théorie des portes. Terminologies Nouvelles, RIFAL, Bélgica, $n^{0}$ 21, p.10-15, Bélgica, 2000. Disponível em: http://termisti.ulb.ac.be/. Acesso em: 12 set. 2020

CERVANTES, B.M.N.; RAIMUNDO, E.M. Análise Terminológica: Termos e Contextos. In: SELISIGNO, 2006, Londrina. Anais... Londrina, UEL, 2006. p. x-y. 
CERVANTES, B.M.N.; RAIMUNDO, E.M.; COSTA, G.C. da; MELLO, L.F. de; VALENTIM, M.L.P. Glossário Trilíngue de Termos em Gestão da Informação. Marília: Fundepe; São Paulo: Cultura Acadêmica, 2010.

DIAS, E. W.; NAVES, M. M. L. Análise de assunto: teoria e prática. 2.ed.rev. Brasília, DF: Briquet de Lemos/Livros, 2013.

DUBUC, R. Manuel Pratique de Terminologie. Quebec, Linguatech, 1985.

ELLE, São Paulo, Abril, fev. 2002. Disponível em: https://elle.com.br/>. Acesso em: 14 set. 2020.

HOUAISS, A. Dicionário Eletrônico Houaiss da língua portuguesa. Rio de Janeiro: Objetiva, 2009.

INTERNACIONAL ORGANIZATION FOR STANDARDIZATION. ISO 1087: Terminology, Vocabulary / Terminologie - Vocabulaire. Genève, 2000.

LARA, M.L.G. Novas relações entre Terminologia e Ciência da Informação na perspectiva de um conceito contemporâneo da informação. DataGramaZero - Revista de Ciência da Informação, Rio de Janeiro, v.7, n.4, ago. 2006.

MALUF, E. Dados técnicos para a indústria têxtil. São Paulo: IPT/ ABIT, 2003.

MANEQUIM, São Paulo, Abril, n. 509, 2002. Disponível em: https://manequim.com.br/ . Acesso em: 14 set. 2020.

OLIVEIRA, S. L. de. Tratado de metodologia científica. São Paulo: Pioneira, 2001.

PAVEL, S.; NOLET, D. Précis de Terminologie. Documentation. Bureau de la Traduction. Direction de la Terminologie et de la Normalisation, Canadá, 2011.

RAIMUNDO, E.M. Um estudo terminológico bilíngue (português-francês) do vocabulário da moda: subárea vestuário. 2003. Dissertação (Mestrado em Estudos da Linguagem) - Programa de PósGraduação em Letras da Universidade Estadual de Londrina. Londrina. 2003.

REY, A. La terminologie: noms et notions. Paris: Presses Universitaires de France, 1979.

RODRIGUES, M. R.; CERVANTES, B. M. N. Identificação de conceitos por meio de mapas conceituais no âmbito da Organização e Representação do Conhecimento. In: XVIII Encontro Nacional de Pesquisa em Ciência da Informação (ENANCIB), Marília/SP, 2017. Anais... Marília/SP: ANCIB: UNESP, 2017.

RONDEAU, G. Introduction à la Terminologie. Québec: Gaëtan Morin, 1984.

WILSON, J. Atividade de análise. In: Pensar com conceitos. São Paulo: Martins Fontes, 2001. p. $1-52$.

WORLD FASHION, São Paulo, fev. 2002. Disponível em: http://www.worldfashion.com.br . Acesso em: 14 set. 2020. 